\title{
As vozes inseparáveis de Czeslaw Milosz
}

\author{
Wladimir Krysinski
}

RÉSUMÉ: La poésie de Czeslaw Milosz touche à la totalité historique, religieuse, politique et artistique de l'humain. Son œuvre se dédouble en une polyphonie de registres lyriques, narratifs, ironiques, confessionnels et paraboliques. En tant que monument à la gloire de la langue polonaise, son œuvre définit un exil qui est à la fois un choix politique et un choix existentiel, philosophique. Milosz est un poète de la mémoire fragmentée, personnelle, subjective mais aussi historique, culturelle et philosophique.

MOTS-CLÉS: histoire, polyphonie, langue polonaise, exil, mémoire.

\author{
Devemos, assim, forjar-nos uma glória \\ anônima, \\ como o grito de adeus que soltam aqueles \\ que partem em direção às trevas.
}

Milosz, "Du livre”, 1934.

\section{Polivocal e universal}

Milosz é um exemplo excepcional na poesia implicada pela totalidade histórica, religiosa, política e artística do humano. Sua obra apresenta-se como o diálogo ininterrupto de uma consciência múltipla, é uma polifonia de registros líricos, narrativos, irônicos, confessionais e parabólicos. É também uma dicção disciplinada, precisa, que carrega o peso da existência humana no mais profundo sentido kantiano do imperativo categórico. Determinante na literatura polonesa ao menos desde 1932, quando foi publicada sua primeira coletânea, intitulada Poema sobre o tempo congela-

Wladimir Krysinski é professor titular de literatura comparada na Universidade de Montreal. 
do, mede-se a importância de Milosz pela justeza de uma voz que, pela primeira vez na Polônia do século XX, exprime suas preocupações metafísicas, com o pressentimento de uma catástrofe iminente. Sua poesia impressiona pela profundeza e pertinência de sua refexão filosófica, pela riqueza e originalidade de seu imaginário, pela intemporalidade de seu simbolismo conjugada com a atualidade imediata e histórica da matéria poética. De uma diversidade impressionante de temas e de formas, essa poesia é animada por uma energia agônica da verdade. Em 1980, Milosz recapitula, paradoxalmente, sua busca poética: "Recomeço sempre, pois minhas narrativas / revelam-se ficção, legível para outrem, mas não para mim; / Ela me amarra e me oculta; / meu desejo de verdade torna-me desonesto" ${ }^{1}$.

Além da poesia, onipotente nessa obra, Milosz é também autor de dois romances traduzidos para inúmeras línguas, A tomada do poder N Nas margens de Issa, como também de vários ensaios dentre os quais destacamos sobretudo os ensaios políticos, como $O$ pensamento cativo, e um texto que é ao mesmo tempo uma espécie de diário íntimo e um relato de viagem: Uma outra Europa. A esses livros, já reconhecidos como clássicos, acrescentam-se numerosos ensaios distribuídos num grande lapso de tempo, desde o início dos anos cinqüenta até os dias de hoje.

\section{A descida aos infernos de si e o comentário da obra}

Poeta incomparável, erudito, paradoxal e unívoco, ao mesmo tempo atormentado, mas de grande disciplina ética, tendo vivido a guerra, atravessado os diferentes classicismos e as vanguardas, poderá Milosz conhecer-se a si mesmo? Em todo o caso, é capaz de refletir sobre si com muita lucidez, consciente de suas experiências e de seus limites. Sem delírios de grandeza, de modo muito espirituoso, o que Milosz diz a respeito de si num livro auto-revelador, Milosz por Milosz ${ }^{2}$, só pode dar vontade de ler o livro em profundidade. Não é nem uma introspecção, nem uma confissão, tampouco uma análise completa de sua obra. E no entanto, este livro é tudo isso, e algo mais. Um extraordinário vade-mecum da época que o poeta atravessou, na qual a paixão por conhecer e o furor da expressão são acompanhados por uma erudição assombrosa e por uma consciência crítica aguda. A descida aos infernos de si representa-se na improbabilidade de

1"Rumo ao fim do século XX". In: Poemas. 1934-1982.

${ }^{2}$ Milosz par Milosz. Entretiens de Czeslaw Milosz avec Czanarcka e Aleksander Fiut. Trad. de Daniel Beauvois. Paris: Fayard, 1986, p......... 
um retrato definitivo, mas ao mesmo tempo faz descobrir um outro ser de sensibilidade à flor da pele, consciente de seus fantasmas e capaz de explicar cada detalhe histórico e fatual de sua poesia, sem pretender saber por que ela se escreveu desta forma e não de outras.

Daí a importância, e até mesmo o culto quase místico, do daimonion pelo qual Milosz revela ser freqüentemente visitado. De Empédocles a Sócrates e de Xenofonte a Platão, esta palavra designa uma presença sobrenatural, um sinal divino ("daimonionti"). Milosz: "O daimonion ditava e eu escrevia: êxtase da união com Deus e ao mesmo tempo com o mundo, sentimento de uma relação excepcional com Deus".

O Estado, que Milosz não tem em grande estima (ver o surpreendente poema "Três diálogos sobre a civilização"), a História e a memória, a Polônia e a Lituânia, a França e a América, a mística e a Cabala, Blake e Dostoievski, eis alguns temas desses diálogos que compõem uma hermenêutica única e talvez também um guia essencial da obra e da época vivida nos confins dos mundos que Milosz, poeta e prosador, ressuscita, fazendo intervir sua memória e palavra contra a crueldade da História.

\section{O exílio e a língua materna}

A obra poética e literária de Czeslaw Milosz é, entre outras coisas, um monumento erigido à glória da língua polonesa. Um monumento de estatura excepcional. Em 1951, Milosz exila-se voluntariamente da Polônia para se estabelecer no Ocidente, inicialmente na França, depois nos Estados Unidos onde, desde 1960 até sua aposentadoria, ensinou literaturas eslavas na Universidade de Berkeley, na Califórnia.

O exílio de Milosz não é unicamente uma opção política, é também uma opção existencial e filosófica. Para o autor de Salvação - título de uma de suas coletâneas de poemas, publicada no imediato pós-guerra, em 1945 -, o exílio simboliza a "condição do homem pós-moderno". "Literalmente e como metáfora”, dirá Milosz, atribuindo o mesmo sentido ao tema do exílio no poeta russo Joseph Brodsky, que vive também nos Estados Unidos. Poeta exilado, esse grande poeta polonês? Mas sim, exatamente como antes dele Adam Mickiewicz, que escreveu sobretudo na Fança e que morreu em 1855 em Constantinopla. O exílio é consubstancial à cultura polonesa. Milosz faz parte de uma população exilada de poloneses que sistematicamente, desde o fim do século XVIII, devia deixar o país natal para se estabelecer uns na França, outros na Alemanha, estes na Inglaterra, aqueles nos Estados Unidos, para mencionar somente os países mais comumente freqüentados pela diáspora polonesa. 
O exílio significa o afastamento espacial da língua materna, mas significa também uma sensibilidade toda particular para essa língua que Milosz, como ele o diz em seu ensaio filosófico publicado em 1977 - A terra de Urla (Ziemia Urlo) - ouve melhor agora que ela está sujeita à pressão das línguas estrangeiras de seu meio e à de seu poliglotismo. A obra de Milosz é um monumento erigido à glória do polonês na medida em que, fiel a sua vocação de poeta e de homem pós-moderno, o escritor exilado faz dela, para seu próprio uso e o de seus leitores, um idioma ao mesmo tempo nacional e cosmopolita. O polonês de Milosz é um instrumento de uma precisão e de uma riqueza inigualáveis. O ouvido percebe nela o eco de vários séculos de poesia polonesa. Ouve também ritmos variáveis, seqüências de fúria e de suavidade, bem como entonações irônicas e sarcásticas que Milosz, bebendo nas fontes da poesia moderna, especialmente em Whitman, Yeats, Eliot e Auden, instala, por assim dizer, no polonês. A língua poética de Milosz constitui-se numa "dicção". Isso ele explica em seu Tratado poético (1957), inspirado no Ensaio sobre a rima (Essay on Rime), do poeta americano Karl Shapiro, e que é, certamente um dos apogeus de sua obra: "Quanto tempo me será suficiente o não sentido / da Polônia, lá onde se escreve a poesia de emoções / com responsabilidade limitada? / Não é a poesia que busco, mas uma nova dicção". Essa nova dicção deve carregar tanto a experiência histórica quanto a sensibilidade pós-moderna.

\section{Labor paciente do poético e o eu em busca do conhecimento}

Milosz cria então uma obra paciente cuja dinâmica não se esfumará jamais e que não recuará perante nenhuma complexidade da situação existencial, nem perante a alienação do homem no século XX. A trajetória dessa obra mede-se por heranças voluntariamente assumidas e por algumas obsessões temáticas. Milosz publicou numerosas coletâneas de poemas, a primeira das quais, mencionada acima, Poema sobre o tempo congelado (1932), inaugura um dos temas particularmente poderosos, o do catastrofismo, que marca, aliás, fortemente a literatura polonesa nos anos 20 e 30 sob a influência da situação internacional. A poesia dos anos 30 exprime, num esplendor de imagens e de metáforas, sua preocupação, seu pressentimento e sua expectativa em relação à catástrofe que iria produzirse em 1939, a deflagração da segunda guerra mundial.

Em Salvação, exprime-se um outro tema, igualmente importante, que impregna sua poesia; é a responsabilidade moral do Poeta diante da huma-

nidade. Esse tema é orquestrado em torno de motivos recorrentes, o da 
crueldade da História, o do poder, o do estado moderno, enfim o da identidade perdida do homem. Poeta da cultura e da natureza, da história e da memória fragmentada, Milosz é antes de mais nada um poeta que só muito dificilmente e muito dolorosamente se resigna à perda do paraíso. Daí a tentativa de ressuscitar o mito da Arcádia que o homem deixou um dia sem poder a ela retornar. Em um dos poemas mais perfeitos em termos de simplicidade, de rigor e de inspiração, "Em Varsóvia” (1945), Milosz afirma: "Terei eu nascido / para me tornar uma carpideira? / Quero cantar os festins / Os bosques alegres nos quais / nos introduzia Shakespeare. Deixai / Aos poetas um instante de alegria / Senão vosso mundo perecerá”.

Esse dilaceramento original do poeta, Milosz o expressa rigorosamente e com uma arte consumada nas coletâneas que sucedem a Salvação, especialmente em A luz do dia (1953) e Tratado poético (1957), que é também e sobretudo uma história da poesia polonesa escrita em versos, de modo irônico. Desde Orei Popiel e outros poemas (1962) até a coletânea Onde o sol se levanta e onde ele se pôe (1974), passando por Gugusse enfeitiçado (1964) et Cidade sem nome (1969), um outro tema se desenvolve, este correlativo ao do paraíso perdido. É a busca da identidade, a procura de um eu permanente e coerente, busca particularmente laboriosa acompanhada de uma reflexão sobre o homem na História e na civilização humana, as quais não são mais dignas desses nomes. A poesia de Milosz torna-se cada vez mais globalizante. Abrese para perspectivas históricas, místicas e geográficas infinitas. Os registros das vozes que se ouvem são múltiplos. A voz profética deve muito à influência declarada do poeta de língua francesa e de inspiração mística que foi o lituano Oscar-Ladislas de Lubicz Milosz, tio de Czeslaw. A terra de Urlo, assim como a poesia recente de Milosz, inspiram-se consideravelmente na poesia e no pensamento místico de Blake e de Swedenborg.

Eu disse que Milosz é um poeta da memória fragmentada. Na procura de um eu autônomo, que possa suportar o peso da História e do mundo cada vez mais desumanizado, essa memória serve de guia. É uma memória pessoal, subjetiva, mas também histórica, cultural e filosófica. Nela estão alojados nomes de homens, de rios, de continentes, de lugares e de obras. Milosz esforça-se por reconstruir uma memória arquetípica, ou melhor, a memória dos arquétipos que garantem uma certeza. Uma certeza de vinculação a um povo, a uma nação, a uma cultura, a uma civilização, enfim, que esqueceu suas origens. Essa busca da memória perdida revela-se por vezes difícil, como mostra este fragmento do poema "Trompas e cítara": "Dirijo-me a ti, minha consciência, quando na noite pesada e riscada / de relâmpagos o avião aterriza em Beauvais ou em Kalamazoo. / Como me alcançarás, majestosa, pesando as faltas e os méritos, eu que não me lembro / mais quem sou nem quem era? / Estou deitado simultaneamente em 
várias orlas, a face sobre a areia e ouço acorrer o Oceano sempre igual tocando tambores extáticos.”

Para Milosz, a busca das origens é o dever do Poeta, porque ele é responsável perante a Humanidade. É um Sábio e deve levantar o peso da vergonha.

\section{Um classicismo moderno e a busca identitária}

A poesia de Milosz define-se sobretudo como uma poesia clássica, consciente de seus fundamentos na civilização mediterrânea. A função do Poeta é assegurar a continuidade dessa civilização num mundo amnésico. Assim: "O poeta europeu ou americano deve estar consciente de que pertence a uma dada civilização que veio à luz nas margens do Mediterrâneo e na qual se fundiram elementos judeus, gregos e romanos. A Grécia e Roma serão, pois, para ele a fonte de temas e de formas."

Além dessa consciência de pertencer a uma origem e a uma herança, Milosz é clássico sobretudo na medida em que há em sua poesia uma persistência de temas atemporais e trans-históricos, como o amor e a morte, como a angústia existencial e o tempo, como a história e a arte. Além e aquém desses temas, há uma imaginação e uma distância muitas vezes irônica, uma posição discursiva de wit que lembra a poesia metafísica inglesa, onde são permitidas todas as surpresas e todos os encantamentos. De fato, estas características de seu discurso fazem dele um bom exemplo do classicismo moderno que Eliot definiu em seus estudos fundamentais, e especialmente em "A tradição e o talento individual".

Já se disse que Milosz é um dos maiores poetas vivos de nossa época e, se entra nesse julgamento um pouco de elogio de conveniência, não se pode negar que a generosidade, a força e a amplidão desta voz tem poucos equivalentes entre os poetas contemporâneos. Voz-testemunha e voz planetária, a poesia de Milosz tem seu lugar ao lado de Pablo Neruda, de SaintJohn Perse, de Seféris, de Boris Pasternak, de Eliot e de Eugenio Montale.

A poesia que segue à atribuição do Prêmio Nobel em 1980 é variada, meditativa, poderosa, complexa e direta; seus sopros cantam a beleza do mundo e a memória do poeta que volta com freqüência a sua infância e ao espaço de felicidade que era para ele sua Lituânia natal. O que impressiona na voz e nas variadíssimas formas desta poesia é a volta da pergunta: "Quem sou eu?", "Quem era eu?”. Escutemos:

Essas vozes que falavam através de mim

São as minhas e não são as minhas, ouvidas de longe. 
Mas quem sou agora, eu, o verdadeiro eu,

Outro que os coros gregos e os ecos devolvidos?

Assim devo eu começar pelo começo,

Libertar-me dos sonhos, ilusões do século?

Nestas margens onde se cala a disputa e o alarido dos juízes

$\mathrm{E}$ eu retorno entre as pessoas há muito esquecidas ${ }^{3}$.

Continuação, portanto, mesmo numa fase avançada de sua vida, de uma busca identitária e de um espanto existencial. O poço da memória e a interrogação ética definem talvez da melhor maneira a presença intensa do "eu" lírico que não cessa de interrogar o mundo, sua memória, e de interrogar-se face ao tempo. A poesia de Milosz é reconhecível por seu tom único em que a sinceridade está lado ao lado com a ironia e a beleza do mundo é dita de forma simples, mas com uma sensibilidade incomparável. Milosz tem o gênio de evocar o instante e o lugar. Sua poesia é profundamente "cronotópica". É também "epifânica" (como o crítico Jan Blonski observou e analisou), já que o surgimento de imagens em Milosz tem, como nas procissões e nos ritos religiosos, uma força assuntiva. Ler Milosz, poeta e ensaísta, é percorrer a topografia física e sensual do mundo; é também aventurar-se no espaço complexo da interioridade humana. Esta, em Milosz, não é de forma alguma a célebre Innerlichkeit romântica. É antes um observatório de onde os olhares são lançados pelo poeta para todos os cantos do mundo, da história e da memória.

\section{Visões californianas e testemunho radical}

Lançando um olhar retrospectivo sobre suas “visões da baía de São Francisco", Milosz reflete sobre a civilização americana através do prisma de sua espiritualidade nesse lugar particular onde pululam as modas. O poeta repensa, pois, sua situação perante a crise dos valores e a busca americana da felicidade: a técnica e a religião, o sexo e a droga, o automóvel e a televisão, as viagens psicodélicas e as utopias comunitárias, o show business e o divertimento. Essa América da pluralidade repetitiva é um espaço de miragens às quais o poeta não tem acesso, justamente por opção ética. Sua voz interpõe-se entre as paixões californianas e o elã da civilização pretensamente

${ }^{3}$ In: Cronikas, do ciclo "Para Heráclito” (1984-1985). 
mais moderna do mundo. $\mathrm{O}$ poeta procura uma verdadeira felicidade e uma verdadeira justiça para a humanidade libertada de seus fetiches tecnocráticos que mascaram o fracasso do paraíso. Num belíssimo poema dirigido fraternalmente a Robinson Jeffers, poeta americano que se tornou eremita por não suportar a "civilização mais moderna do mundo", Milosz dá este conselho: "E no entanto, tu não sabias o que eu sei. A terra ensina / mais coisas que a nudez dos elementos. Ninguém se dá impunemente o olhar de um deus. Tão corajoso na solidão, tu oferecias sacrifícios aos demônios... / Antes esculpir os sóis sobre as junturas de cruz / como se fazia em meu distrito. Às bétulas e aos pinheiros dar prenomes de mulher. Antes implorar a proteção contra a força muda e ardilosa do que anunciar, como tu fizeste, uma coisa inumana" ${ }^{4}$. Nessas visões, as diferentes vozes de Milosz interiorizam a busca de uma mensagem definitiva e segura, de uma frase única que "pese verdadeiramente". Entre uma Europa decepcionante mas atraente e uma América desencadeada, demasiadamente individualista, narcisista, demasiadamente gregária e no impasse de suas ilusões, Milosz opta por uma ética do diálogo com o aqui-e-agora. Em última análise, a América simboliza para ele uma terra de acolhimento onde o desespero confina com o sucesso. A ética de Milosz realiza-se através de um ato duplo, o espanto e a escritura.

\section{Quem poderia ser o Imperador da terra?}

Foi, pois, a América que permitiu à Milosz repensar suas raízes e ver claramente as linhas de força de sua Bildung espiritual, cultural e literária. Imperador da terra ${ }^{5}$ é, pois, um livro exemplar. Contém uma série de ensaios reveladores das afinidades eletivas de Milosz, do soclo ideológico de sua obra. Se à primeira vista nada une Witkiewicz a Simone Weil, o romântico polonês Zygmunt Krasinski a Swedenborg e a Dostoievski, ou Boris Pasternak a Stanislaw Brzozowski, crítico e pensador polonês do início do século XX, é certo, contudo, que Milosz solda as obras deles. Compartilha suas preocupações metafísicas quanto ao destino da civilização humana. Milosz tem o dom de pintar seus retratos humanos e de resumir os temas que lhe falam e que de uma obra a outra se cruzam: a escatologia, o declínio do Ocidente, a exigência moral, o conflito entre o bem e o mal, a consciência religiosa, a história como forma motriz da humanidade. Sem ser humoral

4 " $\ldots \ldots \ldots \ldots \ldots \ldots \ldots \ldots \ldots \ldots \ldots \ldots \ldots . . .$,

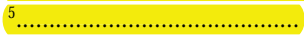


e idiossincrático, Milosz revela-se, entretanto, um crítico ideólogo. Apaixonado pelas Weltanschauungen de seus mestres intelectuais, recorta neles os componentes ideológicos que adapta a seguir em sua obra. A intertextualidade de sua poesia é judiciosamente redefinida pelas imagens e por uma assunção das visões do mundo que o Eu lírico reescreve a seu modo. O denominador comum implícito nesse mosaico reflexivo é, pois, um hipotético "imperador dos povos da terra". Não um novo Messias, mas alguém que prometesse o fim da alienação, o amor e a paz. Habituado ao concreto da História e desconfiado quanto à Utopia, Milosz sabe que esse "imperador" tem seu lugar no imaginário literário. Daí sua paixão pelas grandes figuras emblemáticas da cultura e da literatura, pelos visionários e pensadores negativos, realistas, do concreto.

\section{Poesia, história, real, humanidade}

A distância que separa o poeta outrora catastrofista do pensador e do crítico resume-se por uma tomada de consciência da "humanidade enquanto entidade". A salvação do mundo passa por essa humanidade consciente de si própria, que age em função de seu passado. Milosz precisa: "A humanidade nutrir-se-á cada vez mais de si própria, voltar-se-á cada vez mais para seu passado a fim de procurar nele a chave de seu enigma e penetrar por empatia na alma das gerações e das civilizações findas" ${ }^{6}$.

Testemunho da poesia é escrito e pensado sob a signo da esperança, ainda que a essência dessas seis conferências seja constituída de experiências negativas do poeta moderno, principalmente do poeta polonês que conheceu, exatamente como Milosz, o "inferno do século XX". A persistência da poesia, sua força e sua sobrevivência devem-se a um apego ao real, à História e à memória. Ao apego como testemunho. Daí esta definição paradoxal da poesia: "[...] perseguição da realidade [que] toma forma no pensamento graças à mediação da linguagem". Dostoieveski serve aqui de modelo. Era um "realista" que sabia decifrar os signos. A realidade era para ele constituída de estratos, ela devia ser hierarquizada e mediatizada pela metafísica. O poeta moderno tem muito a aprender de Dostoievski. Milosz acredita no futuro da poesia desde que ela esteja à escuta da complexidade dos signos do real. A poesia polonesa serve aqui de modelo, pois "nela se operou uma fusão particular do individual e do histórico, segundo a qual os acon-

${ }^{6}$ Témoignage de la poésie. Trad. de Christophe Jezewski et Dominique Autrand. Paris: PUF, 1987, p. 
tecimentos que oprimem uma comunidade inteira são percebidos por um poeta como tocando-o de maneira inteiramente pessoal".

\section{História impossível da literatura polonesa}

Para Milosz, a literatura polonesa é exemplarmente universal visto que o escritor polonês teve sempre de enfrentar uma história, uma língua, uma cultura, uma nação, um povo dos mais contraditórios e ricos em incongruências de todos os tipos. Seria demasiadamente longo citar a brilhante síntese de Milosz sobre seu país natal, sua história e sua literatura. Entre todos os retratos dos grandes escritores poloneses, destaca-se o de Cyprian Norwid, contemporâneo de Baudelaire, cuja posição universal e cujo papel formador para a poesia moderna polonesa foram descobertos com aproximadamente um século de atraso. Milosz sintetiza a particularidade das letras polonesas: "O sentido apaixonado da história que Norwid demonstra, sua recusa em praticar uma poesia estreitamente utilitária e, ao mesmo tempo, sua rejeição da "arte pela arte" prepararam o caminho para um gênero específico da literatura que medita sobre a história e sobre a arte, e que é, talvez, exclusivamente polonês" ${ }^{7}$. A História da literatura polonesa de Milosz é altamente compreensível para quem quer que se interesse pela literatura como tal. É um gigantesco quadro que impressiona pela precisão dos detalhes, pela exatidão e pertinência dos julgamentos, pela capacidade de situar os fenômenos literários poloneses num contexto comparativo histórico, cultural, filosófico e literário tão amplo quanto funcional. Através de seu discurso crítico, Milosz marca seu apego a uma língua dinâmica e flexível, maleável e sensível, a um estilo claro e sutilmente irônico, complexo a exemplo do real. Trata-se de uma estratégia discursiva à prova dos acontecimentos que não puderam aniquilar a língua polonesa. $\mathrm{O}$ apego ativo, portanto crítico e dialético, à língua materna é a virtude primeira do poeta em geral. Este é o ensinamento de Milosz. Composta de vozes diversificadas, mas estritamente inseparáveis, a obra de Milosz tende a um equilíbrio instável, como a época que ele se esforça por captar através de sua consciência crítica e criativa.

Traduzido por Tânia Cardoso de Cardoso

${ }^{7}$ History of polish literature. Berkeley: University of Berkeley Press, 19.., p....... 